\title{
MANIFESTAÇÃO DA VIOLÊNCIA NO CONTO ROLÉZIM, DE GIOVANI MARTINS
}

\section{MANIFESTATION OF VIOLENCE IN THE ROLÉZIM tale, BY GIOVANI MARTINS}

\author{
DOI 10.20873/uft2179-3948.2021v12n1p138-151
}

\section{Alexandre Batista da Silva ${ }^{1}$ Elisa Andrade Costa ${ }^{2}$}

\begin{abstract}
Resumo: O presente trabalho analisou a manifestação da violência simbólica no conto Rolézim, parte da obra Sol na cabeça, de Geovane Martins, publicada em 2018. Pela perspectiva de um adolescente, morador da periferia do Rio de Janeiro, narram-se desafios frente ao preconceito e à opressão policial que age sob o discurso da manutenção da ordem. Nesse sentido, a literatura é um importante mecanismo de desvelamento desse tipo de violência, visto que, por meio da ficção, perspectiva o leitor à realidade cotidiana das grandes cidades. Desse modo, buscou-se prescrutar o registro das agressões experimentadas pelas personagens marginalizadas por sua condição social.
\end{abstract}

Palavras-chave: Violência; Cidade; Conto Contemporâneo.

\begin{abstract}
The present work analyzed the manifestation of the symbolic violence in the short story "Rolézim", part of the novel "Sol na cabeça" by Geovane Martins, published in 2018. From the perspective of a teenager, a resident from the outskirts of Rio de Janeiro, challenges facing the prejudice and the police oppression that acts under the speech of order maintenance are narrated. Regarding this matter, literature is an important mechanism for uncovering this kind of violence, since by means of fiction it gives the reader the perspective of the daily reality in big cities. This way, it was sought to investigate the record of aggressions that are experimented by the characters marginalized due to their social condition.
\end{abstract}

Key words: violence; city; contemporary short story.

\section{Introdução}

O presente artigo analisou o conto Rolézim, o primeiro de treze contos do livro Sol na cabeça, de Geovani Martins, publicado em 2018. A ideia foi prescrutar na narrativa do conto

\footnotetext{
${ }^{1}$ Professor doutor em Língua Portuguesa pela Universidade de Federal do Rio de Janeiro. Professor do Curso de Letras do Centro Universitário Geraldo di Biase. E-mail: alexandrebatistasilva1 @ gmail.com

${ }^{2}$ Professora mestra em Literatura Brasileira pela Universidade Federal do Rio de Janeiro. Professora do Curso de Letras do Centro Universitário Geraldo di Biase. E-mail: Elisa.andradevr@yahoo.com.br
} 
como o autor registrou a violência experimentada pelas personagens marginalizadas por sua condição social. Buscou-se, então, a identificação da violência simbólica que atravessa a vida de personagens invisibilizados na sociedade.

Para a definição do conceito de violência não se filiou a nenhuma teoria mais precisamente, mas percorremos diferentes autores que ofereceram uma abordagem interessante ao que se pretendeu nesse artigo. Assim, na primeira seção, foi feita a exposição de como o conceito de violência foi se fundando e de que modo, a partir dele, foram sendo tecidas novas percepções e tipos de violência.

A seção segunda apresentou a análise do conto Rolézim, fazendo cotejos com outros contos do livro, não apenas com a finalidade de apresentar a identificação de um fio condutor dos contos presentes no livro, mas também para apontar o martírio de um grupo social silenciado nas suas dores em diversas situações retratadas nos diferentes contos. Além disso, procurou-se evidenciar que a violência simbólica é a manifestação da cidade partida, na qual os diferentes estratos sociais ocupam diferentes regiões, que os significam e ressignificam constantemente, mas nunca, ou quase nunca, permitem a mobilidade social. Por fim, teceramse considerações finais que não esgotam as possibilidades exploradas, já que o texto é rico em seu potencial semântico.

\section{A violência como conceito e prática}

A violência marca a relação do homem com o ambiente e com seus semelhantes. É por meio dela que ele garantiu sua sobrevivência numa terra igualmente hostil. A estratégia foi construída a partir do controle sobre as forças naturais e, como não poderia deixar de ser, pelo domínio de um grupo humano sobre o outro. É nesse segundo caso que o conceito de violência se funda como tal e sobre o qual se deteve esse artigo, que procura estudar a representação da violência no conto Rolézim, de Geovani Martins.

$\mathrm{Na}$ verdade, procurou-se apontar como a literatura pode dar visibilidade a um tipo de violência de difícil identificação, ou seja, aquela violência não canonizada em práticas que envolvem dor física, sangue ou morte. Para compreender essa dimensão da violência, recorreuse à literatura sobre o estado da arte da violência na sociedade hodierna, procurando uma definição, ainda que provisória, que nos auxiliasse na análise dos contos do livro em tela.

O sociólogo e teórico da comunicação e da cultura Williams (2007) apresenta a multiplicidade de sentidos que a palavra violência compre. O primeiro sentido, mais geral, é aquele que recobre assassinatos, assaltos, sequestros. Esse sentido da palavra violência está 
relacionado com uso da forma física por um agente, o assassino, o assaltante, o sequestrador. Nesse sentido, segundo o autor, é possível apreender outros sentidos não relacionados ao uso da força e ao uso da arma, como instrumento coercitivo.

O autor busca, então, a etimologia da palavra: latim violentia estava associada à veemência, impetuosidade, força. No inglês, teve o sentido de força desde o século 13. Entretanto, o termo também fazia referência à violação, ligado ao rompimento com sistema. Esse último sentido diz respeito a ações nem sempre consideradas como violência, pois a repressão a qualquer tipo de violação é compreendida como tentativa de controle da ordem social. A esse respeito, Odalia (1983) afirma

\begin{abstract}
$\mathrm{O}$ ato violento não traz em si uma etiqueta de identificação. $\mathrm{O}$ mais óbvio dos atos violentos, a agressão física, o tirar a vida de outrem, não é tão simples, pois pode envolver tantas sutilezas e tantas mediações que pode vir a ser descaracterizado como violência. A guerra é um ato violento, o mais violento de todos; talvez, contudo, esse caráter essencial parece passar a ser secundário se o submergirmos sob 27 razões que vão desde a defesa da pátria às incompatibilidades ideológicas. Matar em defesa da honra, qualquer que seja essa honra, em muitas sociedades e grupos sociais, deixa de ser um ato de violência para se converter em ato normal, quando não moral, de preservação de valores que são julgados acima do respeito à vida humana (ODALIA, 1983, p. 23).
\end{abstract}

Essa é a complexidade da definição teórica e prática do que seja violência, uma vez que sua referência pode variar situacional e historicamente. Bonamigo (2008) também observa a origem latina da palavra violência, acentuando o sema bravio, refazendo referência a partir da ideia de vigor e do emprego de força física. O pesquisador assevera que violência só pode ser definida a partir da consideração de critério e ponto de vista (institucionais, jurídicos, sociais e também de ordem individual) atrelados à percepção histórica e cultural.

Além desses sentidos, a palavra está sempre vinculada à criminalidade. Essa vinculação define quando uma ação é considerada violenta. Entretanto, como vimos com Williams (2007), a violência é tema complexo que envolve diferentes aspectos e dimensões sociais. Neste artigo, recortamos os aspectos importantes para sua definição, associando os dois sentidos apresentados por Williams para refletir a questão da violência (e da criminalidade) com o objetivo de identificar, também de forma ampla e pouco exaustiva, sua manifestação nos diferentes lugares sociais, mormente aqueles lugares ocupados pelas personagens retratadas nos contos de Martins.

Assim, de maneira muito ampla e provisória, a violência pode ser entendida como todo comportamento que comprometa não só a integridade física, como aquela presente no primeiro sentido apresentado por Williams, mas também, e talvez sobretudo, aqueles que promovam 
dano, constrangimento ou privação na dimensão psicológica dos indivíduos, como é o caso das personagens dos contos de Martins.

Considerada assim, já se pode estabelecer, de partida, a importante desassociação entre violência e criminalidade, uma vez que nem todo ato violento é considerado crime e nem todo crime é considerado um ato de violência. O isolamento dos dois termos fica evidente quando a violência está relacionada a alguns estratos sociais que historicamente estiveram alijados do que se denomina cidadania. É o caso dos negros, dos homossexuais e, de forma mais dissimulada, da mulher branca que, em determinados períodos da história do Brasil, sofreram diferentes níveis de violência sem que fosse caracterizado crime, ou como, nos tempos atuais, são invisibilizados ou não geram comoção social. Esse foi o caso da escravidão dos negros brasileiros, processo de extrema violência voltada para um grupo social muito bem delineado. Esses tipos de violência estavam dentro da lei, portanto, foram institucionalizados pelo Estado, ou seja, não eram considerados crimes. Assim, quando ligados a determinados grupos alguns crimes serão tolerados e institucionalizados pelos estratos sociais de poder.

Por outro lado, há também alguns tipos de comportamento que são criminalizados, sem, contudo, serem considerados violência. É o caso, por exemplo, do que se denomina vadiagem que, nos termos do artigo 59 do decreto-lei 3.688 de 1941, é uma contravenção identificada como a entrega de uma pessoa ao hábito de ociosidade, relacionado à falta de trabalho, ausência de renda que garanta meios bastantes de subsistência, ou, como ainda diz a lei, "prover à própria subsistência mediante ocupação ilícita". Embora não seja ato violento, podemos dizer, a partir do ângulo da imposição pela força, que a violência está ligada à proibição, que tornou a ociosidade crime por motivação racista ou de classe. Fica evidente a complexidade da definição do que é violência, cujo critério é determinado pelo período histórico e pela cultura.

Michel Foucault (1987) também relativiza o que é violência ao mostrar que o que é considerado crime ou delinquência e quem eram os criminosos (delinquentes) varia ao logo do tempo. Foucault mostra que, ao longo dos períodos históricos, os critérios de violência vão sendo modificados e seus processos podem ser naturalizados numa época e questionados em outras. Por exemplo, no século 17, as penalizações aos crimes eram públicas com o objetivo de tornar a tortura e o sofrimento uma espécie de controle das ações dos membros da sociedade. Com o passar do tempo, essa forma de coerção social foi sendo substituída por outras ações mais privadas de controle. Nesse sentido, some a figura do algoz visível, concreto (que poderia ser combatido, vencido, substituído), e entra uma outra entidade abstrata, impalpável que torna a punição mais velada. (Foucault, 1987; Han, 2015). A esse respeito, diz Foucault: 
Se não é mais ao corpo que se dirige a punição, em suas formas mais duras, sobre o que, então, se exerce? A resposta dos teóricos - daqueles que abriram, por volta de 1780, o período que ainda não se encerrou - é simples, quase evidente. Dir-se-ia inscrita na própria indagação. Pois não é mais o corpo, é a alma. À expiação que tripudia sobre o corpo deve suceder um castigo que atue, profundamente, sobre o coração, o intelecto, a vontade, as disposições. Mably formulou o princípio decisivo: Que o castigo, se assim posso exprimir, fira mais a alma do que o corpo. (FOUCAULT, 1987, p.18)

Essa nova dimensão interessa neste artigo, uma vez que os personagens dos contos em análise sofrem exatamente esse tipo de violência que os tira do jogo social, pune-os com a impossibilidade de acesso aos direitos e, portanto, da possibilidade de mobilidade social. Ainda no rastro da compreensão do que é violência, o filósofo contemporâneo Žižek (2014) assevera que é preciso ampliar o olhar para além da violência evidente , a qual ele chama de subjetiva. Esse tipo de violência é aquela praticada por uma pessoa, portanto, é pessoal e se pode saber quem praticou. Ao tratar desse tema, essa é a primeira percepção de violência que vem à cabeça pois é, fácil de ser identificada por dizer respeito a crimes, sequestros, homicídios, estupros, entre outros. Entretanto, segundo o autor,

Os sinais mais evidentes de violência que nos vêm à mente são atos de crime e terror, confrontos civis, conflitos internacionais. Mas devemos aprender a dar um passo para trás, a desembaraçar-nos do engodo fascinante desta violência "subjetiva" diretamente visível, exercida por um agente claramente identificável. Precisamos ser capazes de perceber os contornos dos cenários que engendram essas explosões. O passo para trás nos permite identificar uma violência que subjaz aos nossos próprios esforços que visam combater a violência e promover a tolerância. (ŽIŽEK, 2014, p. 17)

O segundo tipo de violência é a que Žižek (2014) denomina de objetiva. Esta é, em oposição à primeira, impessoal e anônima. Esse tipo de violência não é praticado por uma pessoa, mas pelo estabelecimento de uma ordem ou padrão por um grupo. Por isso, pode ser chamada também de sistêmica, pois depende de uma lógica estrutural eestá relacionada, por conseguinte, a uma lógica econômica.

Segundo o filósofo, no sistema econômico capitalista, a violência é mais difícil de ser identificada, porque não tem uma fonte, um agente ou uma entidade que a gere, o que a faz parecer natural. Origina-se daí a tendência a negá-la como oriunda do próprio sistema.

Žižek (2014) descreve, ainda, o que ele denomina de violência ultraobjetiva, ou seja, aquela que promove a exclusão automática de algumas pessoas ou grupos sociais, privando-os de suas necessidades básicas e de seus direitos civis. A pobreza, por exemplo, fruto do sistema capitalista, é uma forma de violência, portanto. Nasce também dessa percepção a ideia de violência como mercadoria, o que pode ser demonstrado com o crescimento do comércio de armas e da indústria de segurança privada. Como se pode pressupor, a identificação deste tipo 
de violência é obliterada por um emaranhado de justificativas que naturalizam a violência ou tiram a evidência que a tornaria alvo de combate e resistência.

Além dessas, Žižek (2014) cita, ainda, a violência simbólica. Nesse caso, o filósofo afirma que a própria linguagem pode trazer consequência violenta. Segundo ele, não se trata de a linguagem ser violência em si mesma, mas de corroborar com o estabelecimento das pessoas ou grupos na estrutura social, dando-lhes um determinado valor. Para o filósofo, a linguagem cria uma identidade simbólica que define essas pessoas ou grupos dentro da sociedade. Desse modo, é uma das formas de gerar a violência, embora seja de difícil identificação.

Adorno (1996), acrescenta nesta discussão, o medo como estruturante do comportamento social atual. Para o autor o medo da insegurança é aumentado, exagerado, mas não se relaciona diretamente com a violência, mas com o medo do outro, entendido como o diferente. $\mathrm{O}$ autor chama de intolerabilidade essa relação com o outro, o diferente. No Brasil, esse outro é personificado justamente pelos estratos sociais desprestigiados tais como os negros, os moradores de comunidades, os homossexuais. É este conjunto de ideias que alimenta o que se denomina a indústria do medo, como as empresas de segurança privada ou o controle de entrada de pessoas desses grupos em determinados lugares. Esta pequena incursão no que há de estudos sobre violência fundamentará nossa análise do conto Rolézim, de Martins a partir do conceito de violência simbólica.

\section{O conto Rolézim: um panorama da violência simbólica na cidade do Rio de Janeiro}

Desde Gregório de Matos, a literatura procurou evidenciar os aspectos citadinos, ora sob um viés idealizador, ora mais crítico. A partir do Pré-modernismo, observa-se, progressivamente, a necessidade de desmitificar a imagem da cidade como ambiente que proporciona bem-estar e abriga a modernidade necessária ao indivíduo. Contemporaneamente, as narrativas urbanas revelam justamente a face opressora e excludente deste ambiente que, desde o final do século XIX e início de XX, tenta impor organização e uniformidade a seus habitantes.

Seguindo tal linha crítica, encontra-se nos contos contemporâneos, reunidos sob o título de $O$ sol na cabeça, primeira obra publicada de Geovani Martins, o desnudamento das relações entre classes sociais diferentes. Os treze contos formam um panorama da relação entre os vários ambientes urbanos pela perspectiva de jovens meninos habitantes de periferias do Rio de Janeiro. O habitat marca também a violência desferida a esse grupo marginalizado dos requisitos exigidos pela cidade maravilhosa, mas partida. A fratura se revela desfavorável à 
liberdade daqueles que não conseguem exercer o livre direito de trânsito sem os riscos da opressão policial que se impõe sob o discurso da ordem social.

$\mathrm{O}$ autor, nascido em Bangu, conhecedor da realidade periférica do Rio de Janeiro, revela em sua escrita o cuidado formal ao conciliar técnica e conteúdo. A fluidez com que as falas ocorrem nas ações cotidianas, seguidas de ações diversas, evidencia o percurso de pessoas comuns que lidam com sonhos e frustrações. As belezas e misérias do ambiente urbano se unem em uma grande colcha de retalhos coloridos sob o mesmo sol na cabeça. A unidade, no entanto, se dá apenas externamente, já que as costuras unificadoras de cada fragmento são frágeis e podem se desfazer diante de qualquer passo descuidado em um simples Rolézim.

É nesse sentido que o deslocamento dos jovens em direção à praia no primeiro conto exige cálculos e atenção, principalmente com a força policial. Certamente, não sem motivo, o último texto da coletânea tenha por título Travessia. Entre a saída do espaço em busca de outros rumos e a chegada ao ponto escolhido, a travessia se mostra mais desafiadora, pois há 'um abismo que marca a fronteira entre o morro e o asfalto" que, com o passar do tempo "tornam os muros cada vez maiores.” (MARTINS, p. 11). Essas marcações invisíveis de território denotam a agressividade oculta no mito da não existência da violência no Brasil, segundo Chauí (2017). Dessa forma, um dos mecanismos percebidos seria o da exclusão, que segrega parcela da sociedade entre violenta e não violenta, enquanto outro seria o jurídico, identificador dos “agentes violentos". Ainda segundo a autora, é a partir dos mecanismos jurídicos que é possível

(...)legitimar a ação policial contra a população pobre, os sem-terra, os negros, os indígenas, as crianças sem infância, os moradores de rua, os favelados. (...) No restante das vezes, porém, o assassinato policial é considerado normal e natural, uma vez que se trata de proteger o nós contra o eles. (CHAUÍ, 2017,p. 29)

Essa legitimação é fortemente percebida no tratamento da polícia com os moradores do morro no conto A história do periquito e do papagaio:

Bagulho ficou doido, os polícia sufocando, invadindo casa, esculachando morador por
qualquer bagulho. Tu tá ligado como eles é. Ainda mais com jornal tudo fechando
com eles, tinha que ver. Os maluco achava uma pistola entocada, meia dúzia de
radinho, pronto, já era primeira página, e vagabundo acreditando que eles ia acabar
com o movimento. Tem que ser muito otário, papo reto. Pergunta lá quantos fuzil eles
achou, quantas carga grande, quantos bandido quente eles prendeu. Eu fico de bobeira
quando dou um rolé na pista e vejo que nego não sabe de nada que acontece aqui
dentro. (MARTINS, p. 37,38)

O termo rolé, mais uma vez usado para indicar movimentação para fora, indica as disparidades entre os mundos, bem como a concordância com a repressão pela maioria entendedora de tais atos como protetores. Em sequência, a descrição das agressões deixa mais explícito o cenário repressivo: 
O Cara de Macaco deu logo uma coronhada na cabeça do Neguinho que o melado desceu na hora. Perguntou de novo, disse que se ele num falasse ia meter uma bala na cara dele, ou então que ele ia ter que pular na vala. O Neguinho não pensou duas vez e pulou(...) (MARTINS, p. 40)

Chauí (2017) afirma que um dos mitos da não violência no Brasil se dá devido à declaração, desde cedo, por nossa historiografia "de que nossa história foi feita sem sangue". (p. 26). A literatura, no entanto, nem sempre ofereceu essa visão de país. Sobretudo contemporaneamente, quando a perspectiva da realidade ganha novos tons na arte, é possível entender que a construção de nossa história se faz sobre sangue todos os dias em algum canto oculto e distanciado.

Nesse contexto, o conto Rolézim denuncia a violência oculta sob o signo da necessidade de ordem social imposta, principalmente, pela composição da cidade. Matins retoma o que Alfredo Bosi (1975) denominou de literatura brutalista, nas décadas de 60 e 70, quando expõe cruamente por meio da linguagem e das ações das personagens, a realidade brutal das camadas marginalizadas socialmente.

As narrativas brutalistas encontram no capitalismo o cenário propício ao desenrolar dos diversos conflitos, pois, segundo Bosi (1975) a "sociedade do consumo é, a um só tempo, sofisticada e bárbara. Imagem do caos e da agonia de valores que a tecnocracia produz em um país de Terceiro Mundo." Nesse sentido, a linguagem utilizada representa características dessa literatura "que respira fundo a poluição existencial do capitalismo avançado, de que é ambiguamente secreção e contraveneno, (...) (BOSI, 1975, p.18).” Assim, as falas diretas dos personagens, de forma concisa e objetiva, vão retratando a tensão de classes culminada pela opressão. A brutalidade permeia a história que, não tem por motivação construir a imagem de heróis ou de vilões, mas revelar o desrespeito contínuo aos que se encontram em posição desfavorável na estrutura social e o consequente choque entre opressor e oprimido.

Ao tratar da reforma urbana do Rio de Janeiro em início do século XX, Gomes (1994) afirma que "Cidade e modernidade se pressupõem, na medida em que a cidade é o cenário das mudanças, exibe-as de maneira ostensiva e às vezes brutal. Difunde-as, generaliza-as.” (p.105). A visão do espaço como agente desencadeador do processo de modernização aparece mais uma vez associada à agressão que insiste em igualar ambientes e pessoas. Desse modo, quem foge ao padrão definido por esse ideal, é rejeitado. Nessa perspectiva, Gomes afirma que:

O plano da cidade ideal é a referência para a cidade real. Quantitativamente esta deveria ajustar-se ao valor de qualidade daquela, para atender às demandas das elites. A simetria, porém, se rompe pela ação da "desordem" dos eventos da cidade real que surgem na cena, mesmo enfrentando os mecanismos de controle oficial. (GOMES, 1994, p. 106) 
No conto, isso é mostrado claramente a partir do deslocamento de espaço feito por um grupo de adolescentes. Infere-se que a cidade ideal seria aquela que evitasse a presença de meninos da periferia circulando pela praia, movimento provocador de olhares desconfiados dos playboys e mais atentos da polícia. Essa perfeição sonhada na construção inicial da cidade revela-se segregadora, em busca de uma uniformidade impossível na prática. Dessa maneira, a sucessão de detalhes, aparentemente sem importância, encontra no conto, espaço ideal para esboçar as relações conflituosas em um ambiente hostil às classes desfavorecidas. Tal gênero textual, amplamente utilizado desde o século XIX, manteve o traço de concisão, embora sob novas roupagens. Segundo Alfredo Bosi,

O conto cumpre a seu modo o destino da ficção contemporânea. Posto entre as exigências da narração realista, os apelos da fantasia e as seduções do jogo verbal, ele tem assumido formas de surpreendente variedade. Ora é quase-documento folclórico, ora quase-crônica da vida urbana, ora quase-drama do cotidiano burguês, ora quasepoema do imaginário às voltas, ora, enfim, grafia brilhante e preciosa voltada às festas da linguagem. (BOSI, 1975, p. 7)

Geovani Martins, por meio de cenas vividas por jovens, escreve a quase-crônica da vida urbana em suas nuances socioespaciais. Para isso, vale-se das sensações que permeiam as histórias, desde a agitação pelo encontro com os amigos e promessa de diversão, ao medo aterrador da violência que circunda os personagens.

O trajeto seguido pelos personagens é voltado para ações do dia a dia e se completam formando uma unidade entre as treze narrativas que pintam um painel de relações sociais e os desafios de convivência nesse ambiente. Espiral passa a angústia do narrador que, só mais tarde compreende o olhar de medo dirigido a ele pelas pessoas: "Tudo começou do jeito que eu mais detestava: quando eu, de tão distraído, me assustava com o susto da pessoa e, quando via, era eu o motivo, a ameaça" (MARTINS, p. 11). Entre descobertas e frustrações, a vida acontece nas ruas. São elas que presenciam todas os acontecimentos desde os mais banais como brincadeiras entre crianças aos mais graves desajustes ou embates.

Especialmente em Rolézim, a sinestesia revela a inquietação e movimento provocado pelo forte calor:

Acordei tava ligado o maçarico! Não dava nem mais pra ver as infiltração na sala,
tava tudo seco. Só ficou as mancha: a santa, a pistola e o dinossauro. Já tava dado que
o dia ia ser daqueles que tu anda na rua e vê o céu todo embaçado, tudo se mexendo
que nem alucinação. Pra tu ter uma ideia, até o vento que vinha do ventilador era
quente, que nem o bafo do capeta. (MARTINS, 2018, p. 9)

A necessidade de fugir do problema demonstra a falta de outros meios como dinheiro do pão a ser usado para meio de transporte. Em meio à narrativa, aparecem lembranças de 
recomendações do irmão mais velho sobre o uso de algumas drogas, constituindo micronarrativas que traçam uma espécie de fluxo mental com ideias que se misturam. Em meio a recordações, a polícia aparece, o que demonstra tensão constante com essa categoria:

O Mano de Cinco, que é mó piada também, deu trela, cismou que era os polícia entocado na laje ali do lado, preparando pra dar o bote neles. Mano, os pará peidou na hora, saíram voado, descendo a laje. Foi muito engraçado! Eles andando lá embaixo na rua, tudo escaldado, se escondendo nos muro, com medo dos polícia brotar. ((MARTINS, 2018, p. 11)

O efeito da droga provoca alucinações que envolvem agentes de segurança responsáveis pelo tratamento, tantas vezes, violento e desrespeitoso aos moradores. No entanto, o prazer de estar no local planejado, diante da beleza maior da cidade, em águas refrescantes, minimiza as dores vividas:

Chegamo na praia com o sol estalando, várias novinha pegando uma cor com arabeta pro alto, mó lazer. Saí voado pra água, mandando vários mergulho neurótico, furando as onda. A água tava gostosinha. Nem acreditei quando voltei e vi o bonde todo com cara de cu. O bagulho era que tinha uns cana ali parado, escoltando nós. Tava geral na intenção de apertar o baseado, e os cana ali. Esses polícia de praia é foda. Tem dia que eles fica sufocando legal (MARTINS, 2018, p.12)

Tal momento mais uma vez é ofuscado pela presença dos policiais, que provocam sentimento de desconforto. O plano dos meninos, enfim, após alguns impasses, revela-se vitorioso. Conseguem aproveitar o tempo juntos dividindo a praia com outras muitas pessoas de variadas origens. Contudo, além dos conflitos pelo deslocamento de espaço, há também a problemática que se apresenta pelo tempo. Durante o dia, as ações se dão com mais clareza e segurança. À noite, ao contrário, os sujeitos fora de seu local correm mais riscos, pois ferem os princípios da ordem estabelecida pela parcela que se julga protegida. No retorno, os meninos são abordados por policiais:

Quando nós viu já era quase de noite. Uma larica que, sem neurose, era papo de quarenta mendigo mais vinte crente. Tava na hora de meter o pé. E foi aí que rolou o caô. Nós tava tranquilão andando, quase chegando no ponto já, aí escoltamos os canas dando dura nuns menó. A merda é que um dos cana viu nós também, dava nem pra voltar e pegar outra rua. Mas até então, mano, tava devendo nada a eles, flagrante tava todo na mente, terror nenhum. Seguimo em frente. (MARTINS, 2018, p.18)

O sentimento de medo, controlado pela constatação de que não há nada a temer, pois os meninos não se enquadram em situação ilegal, $\log o$ volta a crescer:

Aí veio com um papo de que quem tivesse sem dinheiro de passagem ia pra delegacia, quem tivesse com muito mais que o da passagem ia pra delegacia, quem tivesse sem identidade ia pra delegacia. Porra, meu sangue ferveu na hora, sem neurose. Pensei, tô fodido; até explicar pra coroa que focinho de porco não é tomada, ela já me engoliu na porrada. Não pensei duas vez, larguei o chinelo lá mermo e saí voado. (MARTINS, 2018, p.15) 
Para Chauí (2017), "as classes populares carregam os estigmas da suspeita, da culpa e da incriminação permanentes", visto que "impera a ideologia segundo a qual a miséria é a causa da violência, as classes ditas desfavorecidas sendo potencialmente consideradas violentas e criminosas." (p. 36). Desse modo, a fuga do menino diante da impossibilidade de saída, simboliza a ausência de opção em situação análoga. O sistema não se preocupa com soluções, já que executa ordens de punir, ainda que não haja culpados.

Rolézim demonstra bem, por meio da separação dos ambientes, periferia e litoral, a delimitação imposta à circulação das pessoas de cada área habitada. Segundo Candido (1963), “a literatura não é uma esfera segregada" e, por mais que necessite se expressar esteticamente, vincula-se à responsabilidade social ao promover reflexões sobre variados temas inerentes ao ser humano e ao seu contexto. Nesse sentido, a narrativa de Martins trabalha a questão social urbana permeada pela violência justificada por pseudonormas que norteiam a ordem. Tal ordenamento se resume à garantia de que a classe desfavorecida, considerada marginalizada, mantenha-se em seu ambiente e não se misture.

Apesar dos entraves sociais, a resistência se mostra na não aceitação de certas imposições, pois o grupo de adolescentes não desiste do direito de ir e vir garantido, ao menos teoricamente, nas leis oficiais do país. Apesar disso, a preocupação com a presença da polícia sempre se manifesta, pois o incessante desconforto com a presença de agentes da lei evidencia a possibilidade de repressão a qualquer momento, por isso, a necessidade de cautela.

O mesmo cuidado, no entanto, não é demonstrado por jovens da classe mais favorecida. No conto, dois deles se drogam tranquilamente nas areias. Tais jovens não demonstram medo das leis vigentes, da polícia, mas do grupo de marginalizados que se encontra ao redor:

O que me deixa mais puto é isso, menó. Tava os dois lá, de bobeira. Aí, quando chegou o Tico mais o Poca Telha pra pedir um bagulho pra eles, na humilde, ficaram de neurose, meio que protegendo a mochila, olhando em volta pra ver se num vinha polícia. Num fode! Tem mais é que ser roubado mermo, esses filhos da puta. Não fosse minha mãe eu ia meter várias paradas na pista, sem neurose, só de raiva. (MARTINS, 2018, p.13)

A violência nesse caso se pauta na ofensa moral manifestada no julgamento que os "play" fazem dos meninos a partir da observação de sua aparência, reveladora de sua origem. Segundo Gomes (1994) certa declaração de Marques Rebelo, em entrevista a Clarice Lispector, sobre o Rio de Janeiro ser "uma cidade com muitas cidades dentro" (...) "aponta também para um todo heterogêneo que resiste à homogeneização do processo moderno.” Assim, é perceptível o inconformismo com a visão preconceituosa manifesta pela raiva da vítima. Por isso, ocupar cenários que rejeitam certos grupos é revelador de enfrentamento ao sistema. 
Ao buscar uma "seda" para enrolar o baseado, o protagonista encontra um vendedor ambulante "responsa" que o aconselha a ter cautela, visto que "os vermes estavam de maldade naqueles dias" (MARTINS, 2018, p.12) devido à morte de um argentino dias antes. Em seguida, afirma a preocupação dos policiais que morresse "mais gente, se pá até um morador ou gringo" (Idem, p14). A passagem, mais uma vez, sinaliza a necessidade de ordenar a segurança daqueles que são aceitos pela cidade em contraposição aos rejeitados. O problema seria a morte de gringos ou de moradores, não a de outros habitantes fora desse ambiente dividido por muros invisíveis.

O conto, desde o título, Rolézim, encaminha o leitor à compreensão da separação de classes que leva em consideração os espaços habitados. Uma simples distração entre adolescentes desencadeia inquietação diante da probabilidade de represália, assim como da humilhação incessante quando estão fora de seu local de vivência. Em cada relato, o personagem descortina as relações e dificuldades de superação do sistema impositivo e segregador. Ainda no século XIX, visionariamente, Machado afirmara que “(...) a literatura não pode ser perfeitamente um culto, um dogma intelectual, e o literato não pode aspirar a uma existência independente, mas sim, tornar-se um homem social, participando dos movimentos da sociedade em que vive e de que depende." ${ }^{3}$ Essa postura de engajamento está claramente exposta na narração feita, já que se vincula à arte, a partir do modo de expressão escolhido, à reflexão crítica e politizadora que provoca no interlocutor, função essencial da literatura em nossos tempos.

\section{Considerações finais}

A arte sempre transcende a simples fruição pelo interlocutor. Na literatura, o prazer da leitura associa-se à transformação das ideias pelas reflexões acerca do mundo e das pessoas que o compõem. Dessa maneira, Geovani Martins, por meio de sua escrita, promove o enriquecimento da percepção das muitas cidades inseridas em uma grande cidade. A cada experiência lida, desmitificam-se ideias preconcebidas em torno do que se entende como violência. Cada personagem salta aos olhos como vida importante, parte de uma coletividade única, e não mais como número frio nos jornais.

\footnotetext{
3 O passado, o presente e o futuro da literatura, In: Obra Completa de Machado de Assis, Rio de Janeiro: Nova Aguilar, vol. III, 1994.
} 
O conto Rolézim, então, enfatiza a percepção do outro, resgatando a humanização perdida pela massificação cotidiana. Como literatura contemporânea, desempenha papel relevante de denúncia e promoção do pensar sobre os problemas sociais, a partir da narrativa ficcional, vinculada a estratégias bem elaboradas em sua construção.

\section{Referências}

ADORNO, S. F. A gestão urbana do medo e a insegurança: Violência, Crime e Justiça Penal na Sociedade Brasileira Contemporânea. Tese de doutorado. Departamento de sociologia da faculdade de Filosofia, Letras e Ciências humanas da Universidade de São Paulo. São Paulo, março 1996.

CANDIDO, A. ROSENFELD; A. PRADO; D. A. \&

GOMES, P. E. S. A Personagem de Ficção. São Paulo: Perspectiva, 1963.

BOSI, Alfredo (org). O conto brasileiro contemporâneo. São Paulo: Cultrix, 1975.

CHAUÍ, Marilena de Souza. (ORG) ITOKAZU, Ericka Marie; CHAUI-BERLINCK, Luciana.

Sobre a violência. Belo Horizonte: Autêntica, 2017.

GOMES, Renato Cordeiro. Todas as cidades, a cidade. Rio de Janeiro: Rocco, 1994.

FOUCAULT, Michel. Vigiar e Punir: nascimento da prisão; tradução de Raquel Ramalhete. Petrópolis, Vozes, 1987.

HAN, B. C. Sociedade do Cansaço. 2a ed. Petrópolis: Editora Vozes, 2015.

ODALIA, Nilo. O que é violência. São Paulo: Brasiliense, 1983.

PELLEGRINI, Tânia. As vozes da violência na cultura brasileira contemporânea. Crítica marxista. Campinas, no 21, p. 132-153, nov. 2005.

SCHØLLHAMMER, Karl Erik. Ficção brasileira contemporânea. Rio de Janeiro: Civilização Brasileira, 2009.

Cenas do Crime: violência e realismo no Brasil contemporâneo. Rio de Janeiro: José Olympio, 2013.

LIMA, Renato Sérgio, Liana de Paula (orgs.). Segurança Púbica e Violência: o Estado está cumprindo o seu papel? São Paulo: Contexto, 2014.

MARTINS, Geovani. $O$ sol na cabeça: contos.1 $1^{\text {eed. }}$-São Paulo: Companhia das Letras, 2018.

WILLIAMS, Raymond. Palavras-Chave: um vocabulário de cultura e sociedade. São Paulo: Boitempo Editorial, 2007. 
ŽIŽEK, Slajov. Violência: seis reflexões laterais. Tradução Miguel Serras Pereira. - Ed.- São Paulo: Boitempo, 2014.

Recebido em 30 de maio de 2021. Aceito em 04 de junho de 2021. 